\title{
$\mathrm{Co}, \mathrm{Cu}$ 가 치환된 $\mathrm{Ni}-\mathrm{Zn}$ 스피넬 페라이트-에폭시 복합체의 제조와 전자기파 흡수 특성 \\ 유지은 · 강영민 * \\ 한국교통대학교 신소재공학전공
}

\section{Fabrication and Electromagnetic wave absorption Properties of Co-Cu-substituted Ni-Zn Spinel Ferrite-epoxy Composites}

\author{
Ji-Eun Yoo and Young-Min Kang* \\ Department of Materials Science and Engineering, Korea National University of Transportation, \\ Chungbuk 27469, Republic of Korea
}

\begin{abstract}
Spinel ferrites $\left(\mathrm{Ni}_{0.5} \mathrm{Zn}_{0.5}\right)_{1-x \cdot y} \mathrm{Co}_{x} \mathrm{Cu}_{y} \mathrm{Fe}_{2} \mathrm{O}_{4},(x=0$ and $y=0, x=0.2$ and $y=0, x=0.1$ and $y=0.1$, $x=0$ and $y=0.2$ ) were prepared by sol-gel method and post-annealed at $1100^{\circ} \mathrm{C}$. The grain growth of the sample is very sensitive to the $\mathrm{Cu}$ substitution $y$. The average grain size of the non-doped sample $(x=0, y$ $=0$ ) was $\sim 400 \mathrm{~nm}$ and it increased to $\sim 3 \mu \mathrm{m}$ at the sample with $x=0$ and $y=0.2$. The real and imaginary parts of permittivities $\left(\varepsilon^{\prime}, \varepsilon^{\prime \prime}\right)$ and permeabilities $\left(\mu^{\prime}, \mu^{\prime \prime}\right)$ were measured on the spinel ferrite powder-epoxy (10 wt\%) composite samples by a network vector analyzer in the frequency range of $0.1 \leq f \leq 15 \mathrm{GHz}$. The $\mu^{\prime}$ and $\mu^{\prime \prime}$ depend on Co substitution $x$ and the $\varepsilon^{\prime}$ is sensitive to Cu doping $y$. Reflection loss (RL), which implies electromagnetic (EM) wave absorption properties, were analyzed based on the complex permeability, permittivity spectra. In the RL map plotted as functions of sample thickness $(d)$ and frequency $(f)$, the intensive EM absorbing area $(\mathrm{RL}<-30 \mathrm{~dB})$ shifted to a high frequency region with increasing Co substitution. This can be attributed to a permeability spectra shift, due to the increase in ferromagnetic resonance frequency produced by the Co substitution. The samples with $x=0.1$ and $y=0.1, x=0.2$ and $y=0$ also exhibited a very broad-ranged EM wave absorbing performance with a $d<3 \mathrm{~mm}$, indicated by $\mathrm{RL}<-10 \mathrm{~dB}$ being satisfied in the frequency range $7 \sim 14 \mathrm{GHz}$.
\end{abstract}

(Received September 8, 2020; Accepted October 18, 2020)

Keywords: Ni-Zn ferrites, permittivity, permeability, Reflection loss, EM absorption

\section{1. 서 론}

최근 스마트폰의 다기능화, 인공지능(AI)과 사물인터넷 (IoT) 기술을 접목한 가전 기기의 확대, 자동차 전장화 시 장의 성장 등으로 인해 우리 주변에 무선 통신을 사용하는 전자기기가 지속적으로 많아지고 있다. 이들 전자기기에서 방출되는 전자기파(EM)의 인체 유해성은 별도로 하고도 원치 않는 전자기파의 회로내 간섭(EMI)으로 인한 소자의 오작동 및 신호 품질 저하가 산업계에 실질적인 이슈가 되

- 유지은: 대학원생, 강영민: 교수

${ }^{*}$ Corresponding Author: Young-Min Kang

[Tel: +82-43-841-5382, E-mail: ymkang@ut.ac.kr]

Copyright $(\mathcal{C}$ The Korean Institute of Metals and Materials
고 있다 [1]. 따라서 전자기파를 적절히 차폐하는 소재에 대한 수요도 꾸준히 증가하고 있다. 전자기파를 차폐하는 방법으로는 반사와 흡수가 있다. 전자기파 차폐능은 차폐 재로 입사한 전자기파 $\left(P_{I}\right)$ 와 투과해 나간 전자기파의 전력 $\left(P_{T}\right)$ 의 비로부터 식1과 같이 도출한다 [2,3]. 전자기파가 차 폐재로 입사될 때 반사에 의한 감쇄 $\left(\mathrm{SE}_{\mathrm{R}}\right)$, 흡수에 의한 감 쇄 $\left(\mathrm{SE}_{\mathrm{A}}\right)$, 차폐재의 내부 반사 $\left(\mathrm{SE}_{\mathrm{B}}\right)$ 를 합한 것으로 총 차폐 가 이루어진다(식2). 금속과 같이 전도성이 우수한 소재의 경우 전자기파의 공기 중 임피던스와 도체 내부의 임피던 스의 차이로 표면에서 반사에 의한 차폐 위주가 된다. 그 러나 반사파가 회로의 다른 부분과 다시 간섭할 수 있는 여지를 가지고 있어 최근에는 전자기파를 흡수하는 방식의 차폐가 다시 주목을 받고 있다 [1]. 


$$
\mathrm{SE}(\mathrm{dB})=10 \log _{10}\left(P_{I} / P_{T}\right)
$$

$$
\mathrm{SE}=S E_{R}+S E_{A}+S E_{B}
$$

전자기파의 흡수 기구(mechanism)로는 도전적인 손실, 유전적인 손실, 자기적인 손실이 있는데 도전적인 손실은 전자파가 도체 내로 입사할 때 순간적으로 미세 전류가 흘 러 도체 자체의 저항으로 인해 열로 변환하여 흡수하는 방 법이고, 유전적인 손실은 전기쌍극자 진동시 발생하는 감 쇠 손실로 복소 유전율의 허수부가 값과 관련이 있다. 전 하가 짧은 거리를 진동하는 고주파에서는 도전적인 손실과 유전적인 손실을 같은 흡수 기구로 볼 수 있다. 자기적인 손실로는 강자성 소재의 자구(magnetic domain) 운동에 기인한 손실과 전자 스핀의 회전시 감쇠운동으로 전자기파 를 흡수하는 것인데 해당 주파수에서 복소 투자율의 허수 부 $\left(\mu^{\prime \prime}\right)$ 값과 관련되어 있다 [1,4-5].

자성 산화물 페라이트 소재 중에서도 스피넬 페라이트는 가격이 저렴하며 자기적 손실 기구에 의해 우수한 전자기 파 흡수 특성을 보인다 [6]. 기본 구조식은 $\mathrm{MFe}_{2} \mathrm{O}_{4}$ 이며 $\mathrm{M}$ 은 2가의 금속이온이다. 이온 반경이 큰 산소이온이 면 심입방격자(fcc)를 형성하고, 산소 이온 배치에 따라 8 개의 사면체 위치(tetrahedral site)와 16개의 팔면체 위치 (octahedral site)를 형성하며 금속이온이 사면체와 팔면체 내의 격자점에 들어가게 되는데 금속이온이 사면체 자리를 차지하면 정 스피넬(normal spinel), 팔면체 자리에 위치하 면 역 스피넬(inversed spinel)이라 하는데 $\mathrm{Ni}-\mathrm{Zn}$ 페라이트 는 정 스피넬 자리에는 $\mathrm{Zn}$ 이온이, 역 스피넬 자리에는 $\mathrm{Ni}$ 이온이 위치해 있어 두 구조가 혼합된 형태(mixed spinel)이며 구조와 이온의 종류에 따라 자기적 성질이 조 절이 가능하다 [7,8]. 스피넬 페라이트 소재는 수 십 년간 직접 회로, 고주파 통신 소재, 센서 등 많은 분야에서 사 용되어 왔으며 꾸준한 연구 개발이 이루어 지고 있다 [9,10]. 그 중 입방정계 스피넬 구조를 가지는 $\mathrm{Ni}-\mathrm{Zn}$ 페라 이트는 우수한 연자성 특성으로 원거리 통신기, 마이크로 디바이스, 전자파 흡수체 등으로 응용되어 왔다. 또한 수 수백 $\mathrm{MHz}$ 대역에서 높은 복소투자율 값 $\left(\mu=\mu^{\prime}+j \mu^{\prime \prime}\right)$ 과 높은 전기 비저항 값을 가지고 있어 해당 주파수 대역 에서 EMI 차폐 및 흡수 소재로 활용성이 뛰어나다 [1115]. Ni-Zn 페라이트는 고상법(solid-state reaction) $[16,17]$, 공침법(co-precipitation method) $[18,19]$, 졸겔법 (sol-gel method) [15,20,21] 등 다양한 합성 방법이 있다. 이 중 졸겔법은 배위화합물이 원자간의 결합을 끊어 다원 소 화합물을 합성하는데 용이하고, 고상법과 비교했을 때
열처리 온도가 상대적으로 낮고 비교적 단순한 공정으로 나노 사이즈의 결정분말을 얻을 수 있는 장점이 있다. Ni$\mathrm{Zn}$ 페라이트 중 졸겔법을 활용해 합성한 뒤 복합체나 소 결체의 전자파 흡수 특성을 평가한 연구 결과들을 표 1 에 정리하였다 [22-27]. 대부분의 실험에서 샘플에 고분자 바 인더를 혼합하여 복합화한 후 복소 투자율과 복소 유전율 을 측정하였다. 소결체에서는 수 수백 $\mathrm{MHz}$ 범위에서 투 자율 허수부의 peak을 보이나 나노 결정의 입자들로 제조 될 경우 투자율의 크기는 감소하나 수 십 수 $\mathrm{GHz}$ 까지 활 용 가능한 흡수체로서의 특성을 보였다. 고분자와 페라이 트 입자의 복합체의 경우 소결체 보다 형상을 쉽게 가공하 고 유연한 시트로 제작할 수 있어 실제 제품 적용에 유리 하다.

스피넬 페라이트 소재의 자기적 특성에 대한 연구와 전 자파 흡수 특성에 대한 많은 연구가 개별적으로 보고되었 음에도 고주파에서 자성 특성의 변화와 흡수 특성 간의 상 관 관계를 체계적으로 연구한 결과는 찾기가 어렵다. 본 연구에서는 조성 치환에 따른 자기적 특성 변화와 이에 따 른 전자기파 흡수 특성의 변화에 대한 상관 관계를 연구하 고자 하였다. 본 연구팀에의 선행 연구에서 $\mathrm{Ni}-\mathrm{Zn}$ 페라이 트 $\left(\mathrm{Ni}_{x} \mathrm{Zn}_{1-x} \mathrm{Fe}_{2} \mathrm{O}_{4}\right)$-에폭시 복합체의 혼합비와 결정화 온도 및 자성 분말의 크기에 따른 고주파 투자율 특성 변화, 그 리고 이에 따른 전자기파 흡수 특성을 보고하였다 [28,29]. 또한 고상법으로 합성한 $\mathrm{Ni}-\mathrm{Zn}$ 페라이트 소결체에 다양한 양이온을 첨가하여 복소 투자율 spectra의 변화를 평가하 였는데, 그 중 $\mathrm{Co}$ 와 $\mathrm{Cu}$ 을 동시에 첨가하였을 때 효과적인 자기특성과 미세구조의 변화를 얻을 수 있었다 [30]. 본 연구에서는 선행 연구에서 최적화된 공정 조건들로, 곧, 자 성 분말의 결정화 온도, 에폭시 함량, 양이온 첨가물 영향 에 따른 결과를 바탕으로 $\mathrm{Co}$ 와 $\mathrm{Cu}$ 를 동시에 치환한

Table 1. EM absorption properties of spinel ferrites - fraction of the magnetic particle in the polymer composite $\left(f_{m p}\right)$, minimum reflection loss $\left(\mathrm{RL}_{\min }\right)$, thickness $(d)$ and frequency $\left(f_{\text {RLmin }}\right)$ at the minimum reflection loss [22-27].

\begin{tabular}{lccccc}
\hline \multicolumn{1}{c}{ Composition } & $\boldsymbol{f}_{\boldsymbol{m} \boldsymbol{p}}$ & $\begin{array}{c}\boldsymbol{R} \boldsymbol{L}_{\text {min }} \\
(\mathbf{d B})\end{array}$ & $\begin{array}{c}\boldsymbol{d} \\
(\mathbf{m m})\end{array}$ & $\begin{array}{c}\boldsymbol{f}_{\boldsymbol{R} \boldsymbol{L} \text { min }} \\
(\mathbf{G H z})\end{array}$ & refs \\
\hline $\mathrm{Ni}_{0.5} \mathrm{Zn}_{0.5} \mathrm{Fe}_{2} \mathrm{O}_{4}$ & $70 \mathrm{wt} \%$ & -29.6 & 5 & 6.5 & {$[22]$} \\
$\mathrm{Ni}_{0.5} \mathrm{Zn}_{0.4} \mathrm{Mg}_{0.1} \mathrm{La}_{0.01} \mathrm{Fe}_{1.99} \mathrm{O}_{4}$ & $60 \mathrm{wt} \%$ & -10 & 3 & 13.7 & {$[23]$} \\
$\mathrm{Ni}_{0.7} \mathrm{Zn}_{0.3} \mathrm{Fe}_{2} \mathrm{O}_{4}$ & $70 \mathrm{wt} \%$ & -24.5 & 2.5 & 8.5 & {$[24]$} \\
$\mathrm{Ni}_{0.7} \mathrm{Zn}_{0.3} \mathrm{Y}_{0.2} \mathrm{Fe}_{1.8} \mathrm{O}_{4}$ & $70 \mathrm{wt} \%$ & -34.8 & 2.5 & 8 & {$[24]$} \\
$\mathrm{ZnFe}_{2} \mathrm{O}_{4}$ & $100 \%$ & -15 & 120 & 9 & {$[25]$} \\
$\mathrm{Ni}_{0.3} \mathrm{Cu}_{0.2} \mathrm{Zn}_{0.5} \mathrm{Fe}_{2} \mathrm{O}_{4}$ & $85 \mathrm{vol} \%$ & -12.7 & 3 & 13.8 & {$[26]$} \\
$\mathrm{Ni}_{0.4} \mathrm{Co}_{0.2} \mathrm{Zn}_{0.4} \mathrm{Fe}_{2} \mathrm{O}_{4}$ & $85 \mathrm{vol} \%$ & -13.2 & 3 & 14.0 & {$[26]$} \\
$\left(\mathrm{Ni}_{0.407} \mathrm{Co}_{0.207} \mathrm{Zn}_{0.386}\right) \mathrm{Fe}_{2} \mathrm{O}_{4}$ & $100 \%$ & -58 & 6.5 & 2.6 & {$[27]$} \\
\hline
\end{tabular}


$\left(\mathrm{Ni}_{0.5} \mathrm{Zn}_{0.5}\right)_{1-x-y} \mathrm{Co}_{x} \mathrm{Cu}_{y} \mathrm{Fe}_{2} \mathrm{O}_{4}$ 조성에서 치환 원소에 따른 미 세 구조의 변화 고주파 특성 및 전자기파 흡수 특성이 어 떻게 변화하는지 체계적으로 연구하였다.

\section{2. 실험방법}

\section{1 샘플의 제조 과정}

졸겔법을 이용하여 스피넬 페라이트 상을 합성하였다. 출 발원료는 $\mathrm{Ni}\left(\mathrm{NO}_{3}\right)_{2} \cdot 6 \mathrm{H}_{2} \mathrm{O}(99 \%), \mathrm{Zn}\left(\mathrm{NO}_{3}\right)_{2} \cdot 6 \mathrm{H}_{2} \mathrm{O}(98 \%)$, $\mathrm{Fe}\left(\mathrm{NO}_{3}\right)_{2} \cdot 9 \mathrm{H}_{2} \mathrm{O}(99+\%)$ 를 사용하여, 양이온의 몰 비가 $\left(\mathrm{Ni}_{0.5} \mathrm{Zn}_{0.5}\right)_{1-x-y} \mathrm{Co}_{x} \mathrm{Cu}_{y} \mathrm{Fe}_{2} \mathrm{O}_{4}(x=0$ and $y=0, x=0.2$ and $y=0, x=0.1$ and $y=0.1, x=0$ and $y=0.2$ )의 4 개의 서로 다른 조성으로 화학 양론적으로 맞게 칙량하여 citric acid $\left(\mathrm{C}_{6} \mathrm{H}_{8} \mathrm{O}_{7} \cdot \mathrm{H}_{2} \mathrm{O}\right)$ 를 1대 1 의 무게비로 넣어 혼합하였다. 혼합된 분말에 최소한의 증류수를 넣어 용해하고, 암모니 아수 $\left(\mathrm{NH}_{4} \mathrm{OH}\right)$ 를 용액에 첨가하여 $\mathrm{PH}$ 7을 맞춘 후 $100{ }^{\circ} \mathrm{C}$ 에서 혼합된 용액이 증발하여 연소 될 때까지 교반 시켰다. 연소된 분말을 오븐에 넣고 $180{ }^{\circ} \mathrm{C}$ 에서 24 시간 건 조시켰다. 건조가 완료된 샘플들을 각각 알루미나 도가니 에 담아 $1100{ }^{\circ} \mathrm{C}$ 공기 중에서 각각 4시간씩 열처리하였다. 열처리가 끝난 각 조성의 스피넬 분말과 고형 epoxy (YD-014, 국도화학)를 9대1 무게비로 혼합 및 분쇄한 후 toroidal 형태인 몰드(내경 $3.03 \mathrm{~mm}$, 외경 $7.00 \mathrm{~mm}$ )에 각 각 $0.15 \mathrm{~g}$ 씩 넣고 0.5 ton의 압력을 주어 성형한 뒤 $180{ }^{\circ} \mathrm{C}$ 에서 20 분 동안 경화시켰다.

\section{2 특성 평과 방법}

$\mathrm{X}$-선 회절분석기 (XRD, D8-Adcance, Bruker)를 사용하 여 시료의 결정구조를 확인하였고 (타겟: $\mathrm{Cu} \mathrm{K} \mathrm{K}_{\alpha}(\lambda=$ $0.154056 \mathrm{~nm}))$, 시료의 미세 구조와 입자 크기를 전계방사 형 주사 전자현미경(FE-SEM, JSM-7610F, JEOL)을 이용 하여 관찰하였다. 소결체-에폭시 복합체의 복소 투자율의 실수부 $\left(\mu^{\prime}\right)$ 및 허수부 $\left(\mu^{\prime \prime}\right)$ 와 복소 유전율의 실수부 $\left(\varepsilon^{\prime}\right)$ 및 허수부 $\left(\varepsilon^{\prime \prime}\right)$ 는 내경 $3.04 \mathrm{~mm}$, 외경 $7.00 \mathrm{~mm}$, 두께 $3 \mathrm{~mm}$ 내외로 최종 가공된 toroidal 샘플에 대해 벡터 네

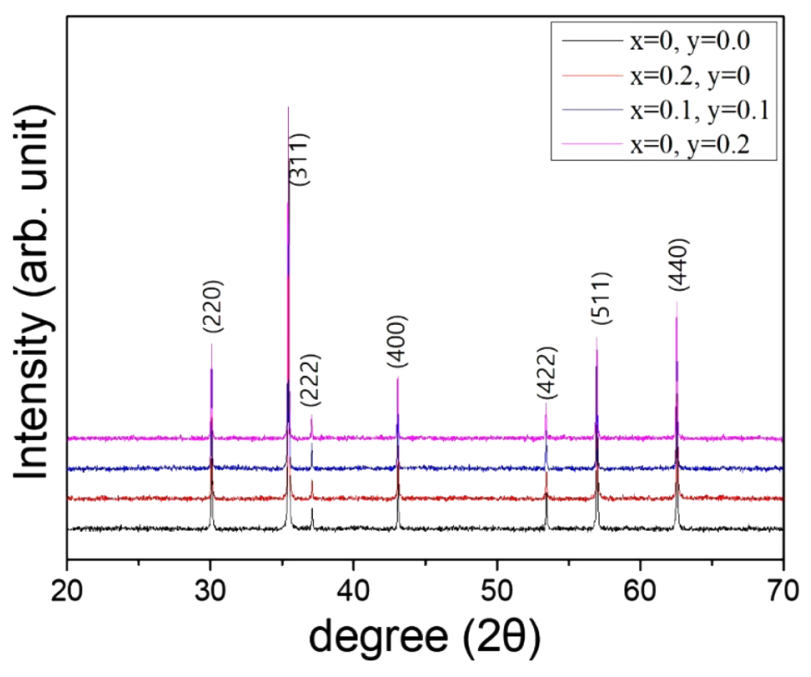

Fig. 1. XRD patterns of $\left(\mathrm{Ni}_{0.5} \mathrm{Zn}_{0.5}\right)_{1-x-y} \mathrm{Co}_{x} \mathrm{Cu}_{y} \mathrm{Fe}_{2} \mathrm{O}_{4}(x=0$ and $y=$ $0, x=0.2$ and $y=0, x=0.1$ and $y=0.1, x=0$ and $y=0.2$ ).

트워크 분석기(Vector Network Analyzer, E50356A, Keysight)를 에어라인 (air-line) 키트 (85052BR03)와 함께 사용하여 $0.1 \sim 15 \mathrm{GHz}$ 주파수 구간에서 측정하였다.

\section{3. 결과 및 고찰}

\section{1 결정구조 및 미세구조 평가}

그림 1 은 $\mathrm{Ni}_{0.5} \mathrm{Zn}_{0.5} \mathrm{Fe}_{2} \mathrm{O}_{4}$ 의 $\mathrm{Ni}-\mathrm{Zn}$ 자리에 $\mathrm{Co}$ 와 $\mathrm{Cu}$ 가 각각 치환된 조성 $\left(\mathrm{Ni}_{0.5} \mathrm{Zn}_{0.5}\right)_{1-x-y} \mathrm{Co}_{x} \mathrm{Cu}_{y} \mathrm{Fe}_{2} \mathrm{O}_{4}(x=0$ and $y=0, x=0.2$ and $y=0, x=0.1$ and $y=0.1, x=0$ and $y=0.2$ )를 졸겔법으로 합성 후 공기 중에서 $1100{ }^{\circ} \mathrm{C}$ 로 4 시 간 열처리한 샘플의 X-선 회절 패턴을 보여준다. 모두 단 상의 스피넬 상이 확인됨으로 $\mathrm{Co}$ 와 $\mathrm{Cu}$ 가 스피넬 상 내로 잘 치환됨을 알 수 있다. 격자 상수 $(\AA)$ 와 단위셀의 부피 $\left(\AA^{3}\right)$ 를 $2 \theta$ 각을 바탕으로 계산하여 표 2에 나타내었다. $\mathrm{Co}^{2+}$ 가 $x=0.2, \mathrm{Cu}^{2+}$ 가 미치환 $(y=0)$ 되었을 때 격자 상수가 가장 크게 얻어졌다. 이는 $\mathrm{Co}^{2+}$ 의 이온 반경 $(0.74$ $\AA$ )이 $\mathrm{Ni}^{2+}$ 와 $\mathrm{Zn}^{2+}$ 의 평균 이온 반경보다 크고 $\mathrm{Cu}^{2+}$ 의 이

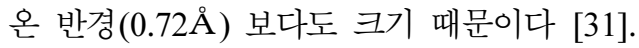

Table 2. lattice parameter (a), lattice volume (vol.), real part of permittivity $\left(\varepsilon^{\prime}\right)$ at $1 \mathrm{GHz}$, imaginary part of permittivity $\left(\varepsilon^{\prime \prime}\right)$ at $1 \mathrm{GHz}$, real part of permeability $\left(\mu_{s}^{\prime}\right)$ at $100 \mathrm{MHz}$, maximum imaginary part of permeability $\left(\mu_{\text {max }}^{\prime \prime}\right)$, and the frequency $\left(f_{\mu^{\prime \prime} \text { max }}\right)$ at the maximum $\mu^{\prime \prime}$ of $\left(\mathrm{Ni}_{0.5} \mathrm{Zn}_{0.5}\right)_{1-x-y} \mathrm{Co}_{x} \mathrm{Cu}_{y} \mathrm{Fe}_{2} \mathrm{O}_{4}(x=0$ and $y=0, x=0.2$ and $y=0, x=0.1$ and $y=0.1, x=0$ and $y=0.2)$ samples.

\begin{tabular}{|c|c|c|c|c|c|c|c|c|}
\hline$x$ & $y$ & $\begin{array}{c}\mathbf{a} \\
(\AA)\end{array}$ & $\begin{array}{l}\text { Vol } \\
\left(\AA^{3}\right)\end{array}$ & $\begin{array}{c}\varepsilon^{\prime} \\
\text { (@) } 1 \mathrm{GHz})\end{array}$ & $\begin{array}{c}\varepsilon^{\prime \prime} \\
(@ 1 G H z)\end{array}$ & $\begin{array}{c}\mu^{\prime} \\
(@ 100 \mathrm{MHz})\end{array}$ & $\mu^{\prime \prime}{ }_{\max }$ & $\begin{array}{l}f_{\mu^{\prime \prime} \max } \\
(\mathbf{G H z})\end{array}$ \\
\hline 0 & 0 & 8.389 & 590.4 & 5.266 & 0.166 & 7.465 & 2.62 & 0.55 \\
\hline 0.2 & 0 & 8.395 & 591.6 & 5.605 & 0.192 & 4.149 & 1.34 & 1.81 \\
\hline 0.1 & 0.1 & 8.392 & 591.1 & 6.331 & 0.214 & 5.393 & 1.68 & 1.81 \\
\hline 0 & 0.2 & 8.391 & 590.8 & 6.537 & 0.196 & 7.811 & 2.79 & 0.73 \\
\hline
\end{tabular}



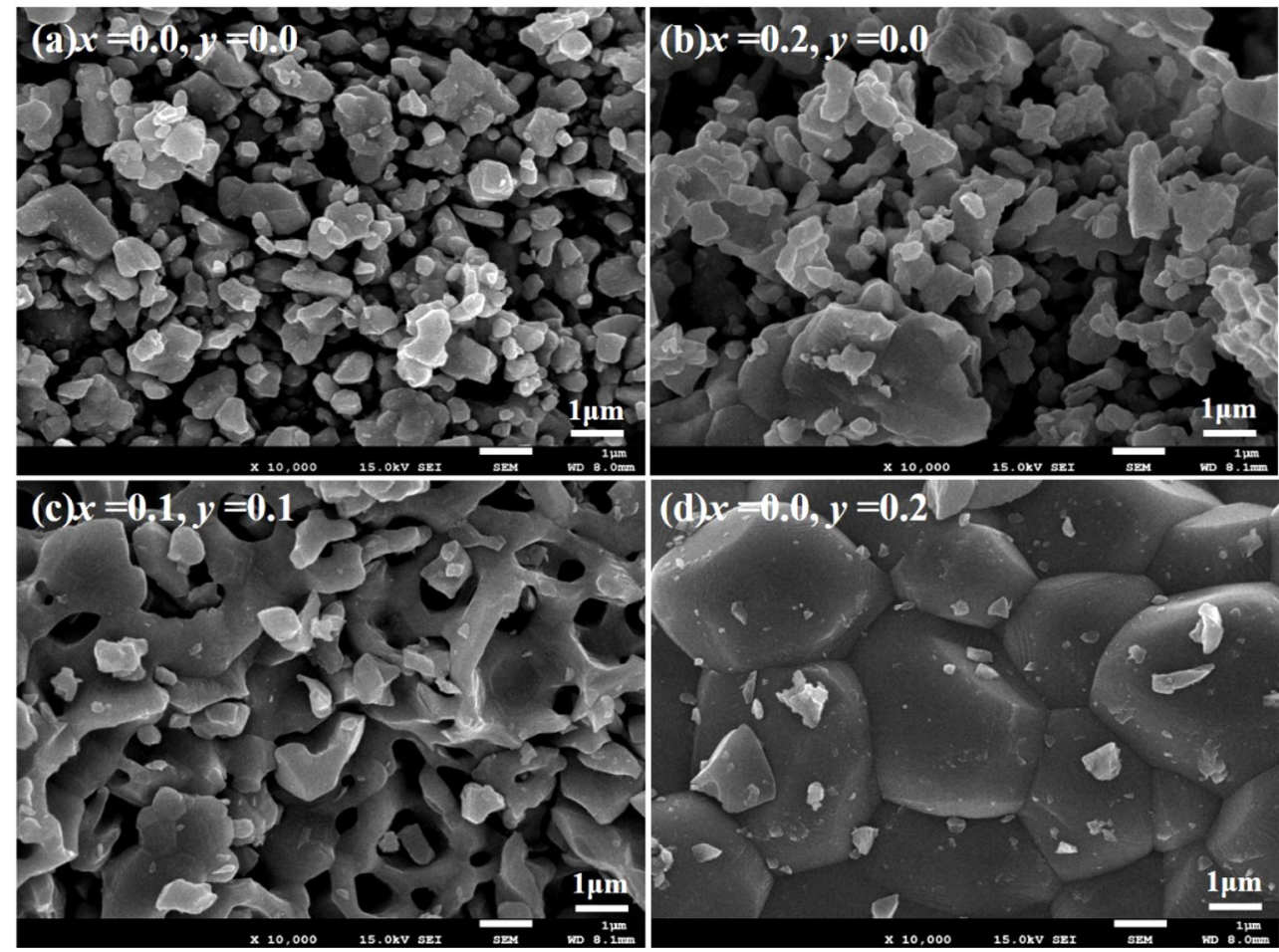

Fig. 2. SEM micrographs of $\left(\mathrm{Ni}_{0.5} \mathrm{Zn}_{0.5}\right)_{1-x-y} \mathrm{Co}_{x} \mathrm{Cu}_{y} \mathrm{Fe}_{2} \mathrm{O}_{4}(x=0$ and $y=0, x=0.2$ and $y=0, x=0.1$ and $y=0.1, x=0$ and $y=0.2)$ samples annealed at $1100{ }^{\circ} \mathrm{C}$.

그림 2는 $\mathrm{Co}$ 와 $\mathrm{Cu}$ 를 치환한 $\mathrm{Ni}-\mathrm{Zn}$ 페라이트 샘플들의 $1100{ }^{\circ} \mathrm{C}$ 열처리 후 촬영한 $\mathrm{SEM}$ 사진이다. 그림 2(a)의 $\mathrm{Co}$ 와 $\mathrm{Cu}$ 를 치환하지 않은 샘플 $(x=0.0$ and $y=0.0)$ 의 경 우 평균 결정립 크기가 $400 \mathrm{~nm}$ 정도로 가장 미세하였으며 결정 입자들 간에 서로 떨어져 있는 형태를 보인다. 그림 2(b)의 $\mathrm{Co}$ 를 치환한 샘플에서는 결정립들이 미치환 샘플과 대체로 유사하나 일부 결정립은 $1 \mu \mathrm{m}$ 이상으로 성장한 것 을 알 수 있고 결정립들간 서로 결합하여 clustering을 이 루고 있는 형태임을 알 수 있다. 그림 2(c) $\mathrm{Co}$ 와 $\mathrm{Cu}$ 가 각각 $x=0.1$ 씩 치환된 경우로 결정립이 성장하고 서로 necking에 의해 연결된 구조를 보이고 결정립들 간에 기공 들도 보인다. 그림 $2(\mathrm{~d})$ 의 $\mathrm{Cu}$ 를 $x=0.2$ 치환한 경우 결정 립들이 대부분 크게 성장하여 평균 결정립의 크기가 $3 \mu \mathrm{m}$ 이며 서로 치밀하게 결합된 형태를 보인다. $\mathrm{Co}$ 도 입성장 에 기여하는 경향이 있으나 $\mathrm{Cu}$ 의 첨가가 스피넬 결정상의 성장에 주로 기여하는 것으로 판단된다.

\section{2 고주파 유전율 및 투자율 특성 평가}

그림 3(a)-3(d)은 스피넬 페라이트 분말-에폭시 복합체 샘플의 복소 유전율 $\left(\varepsilon^{\prime}, \varepsilon^{\prime \prime}\right)$ 및 복소 투자율 $\left(\mu^{\prime}, \mu^{\prime \prime}\right)$ spectra를 보여준다. 그림 3(a) 유전율의 실수부 $\left(\varepsilon^{\prime}\right)$ 값은
측정 주파수 범위에서 큰 변화 없이 유지되는 형태로, 그 크기는 비치환 조성 $(x=0$ and $y=0)$ 일 때 가장 낮은 값 $\left(\varepsilon^{\prime} \sim 5.3\right)$ 을 보이고 $\mathrm{Co}$ 가 치환되었을 때 $(x=0.2$ and $y=0)$ 소폭 상승하며 $\mathrm{Cu}$ 가 치환되었을 때 $(x=0$ and $y=0.2)$ ) 더 크게 증가함을 알 수 있다. 그림 $3(\mathrm{~b})$ 의 유전 율 허수부 $\left(\varepsilon^{\prime \prime}\right)$ 값은 조성에 관련 없이 거의 $0 \sim 0.2$ 범 위로 낮은 값을 보이는데 이는 스피넬 페라이트의 높은 절 연 특성과 관련이 있다. $10 \mathrm{GHz}$ 이상에서의 보이는 peak 들은 측정 노이즈로 판단된다. 그림 3(c)의 투자율의 실수 부 $\left(\mu^{\prime}\right)$ spectra는 측정 주파수 범위에서 지속적으로 감소 하는 형태를 공통적으로 보이는데 $0.1 \sim 1 \mathrm{GHz}$ 정도의 낮은 주파수 범위에서는 비치환 샘플 보다 $\mathrm{Cu}$ 가 치환된 샘플 $(x$ $=0$ and $y=0.2$ )에서 소폭 더 높은 값을 보이고 $\mathrm{Co}$ 가 치 환될수록 높이가 낮아짐을 알 수 있다. 이러한 투자율의 조성에 따른 변화는 자벽(magnetic domain wall)의 이동 에 영향을 미치는 결정입계의 크기와도 관련이 있겠으나 치환에 의한 결정자기 이방성의 변화가 주요한 원인으로 판단된다 [31]. 실제 비치환 $(x=0$ and $y=0)$ 자성 분말 과 $\mathrm{Cu}$ 만 치환 $(x=0$ and $y=0.2)$ 된 자성분말의 미세구조 상에는 그림 2(a), 2(d))에 확인 되는 바로 매우 큰 차이 가 있으나 고주파 $\mu^{\prime}, \mu^{\prime \prime}$ spectra는 모두 크게 변화하지 
않았다. 이는 투자율에 기여하는 요소가 거시적 기구인 자 벽의 운동과 미시적 기구인 전자의 스핀 운동으로 나눌 수 있는데 $\mathrm{GHz}$ 이상 대역의 고주파에서는 자벽의 운동보다 는 전자 스핀이 주로 투자율에 기여하기 때문이다 [32]. 또한 $\mathrm{Cu}$ 치환 보다는 $\mathrm{Co}$ 의 치환이 투자율 특성 변화에 주요한 영향을 미치는 것으로 확인되는데, $\mathrm{Co}$ 가 치환될수 록 결정자기이방성이 증가하기 때문이다. 이에 따라 강자 성 공명 주파수가 증가하면서 보다 고주파까지 $\mu^{\prime}>1$ 을 유 지하고 저주파에서의 $\mu^{\prime}$ 의 높이 (또는 $\mathrm{dc}$ 자장에서의 얻어 지는 static 투자율 $\left.\mu_{s}^{\prime}\right)$ 는 낮아진다. 그림 $3(\mathrm{~d})$ 의 투자율 허수부 spectra에서 강자성 공명주파수에 해당하는 peak의 최대점을 보이는 주파수가 $\mathrm{Co}$ 가 치환될수록 고주파 방향 으로 이동해 가는 것을 확인 할 수 있다. 이상의 결과는 아래 식 (3)의 이방성 자계 $\left(H_{a}\right)$ 와 강자성 공명 주파수 $\left(f_{r}\right)$ 의 비례 관계와 식 (4)의 Snoek's limit law로 해석할 수 있다 [33,34].

$$
\begin{aligned}
& f_{r}=\frac{\gamma H_{a}}{2 \pi} \\
& \left(\mu_{s}^{\prime}-1\right) \cdot f_{\mathrm{r}}=\frac{2}{3} \gamma \cdot 4 \pi M_{s}
\end{aligned}
$$
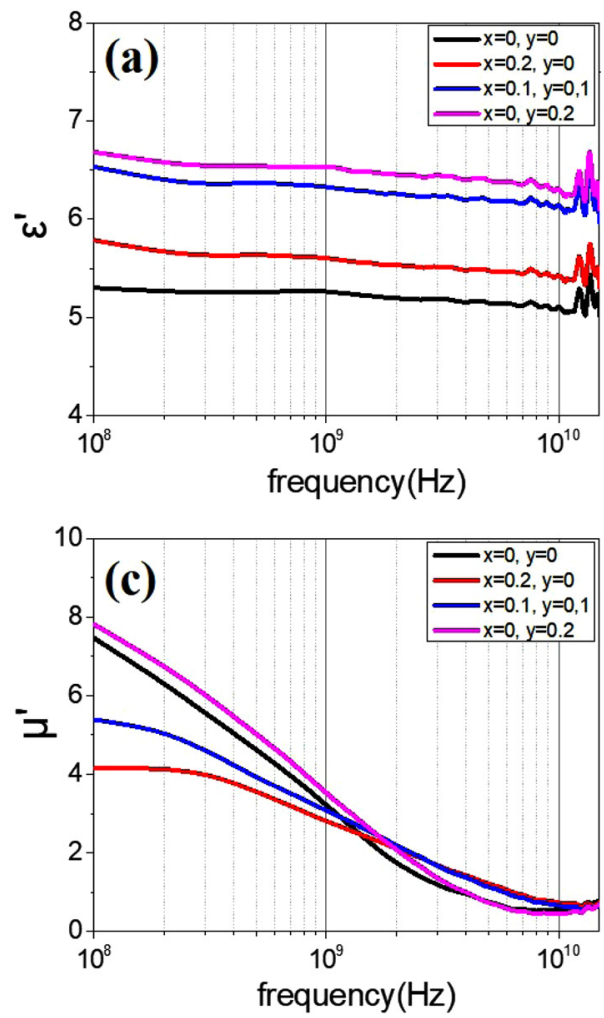

여기서 $\gamma$ 는 자기회전비 상수이며, $M_{S}$ 는 포화자화이다. 이 방성 자계 $\left(H_{a}\right)$ 는 결정자기이방성 상수 $\mathrm{K}$ 와 비례 관계에 있 다. 그림 3 에서 얻어진 $1 \mathrm{GHz}$ 에서 유전율의 실수부 $\left(\varepsilon^{\prime}\right)$ 값과 허수부 $\left(\varepsilon^{\prime \prime}\right)$ 값, $100 \mathrm{MHz}$ 에서 투자율의 실수부 $\left(\mu^{\prime}\right)$ 값과 투자율 허수부의 최대값 $\left(\mu^{\prime \prime}{ }_{\max }\right)$ 과 그 때의 주파수 값 을 $\left(f_{\mu^{\prime \prime} \max }\right)$ 표 2에 제시하였다.

\section{3 전자기파 흡수 특성 평가}

그림 4 (a)-4(d)의 주파수에 따라 측정된 복소 유전율 $\left(\varepsilon_{r}=\varepsilon^{\prime}-j \varepsilon^{\prime \prime}\right)$ 과 복소 투자율 $\left(\mu_{r}=\mu^{\prime}-j \mu^{\prime \prime}\right)$ 값으로부터 전 자기파 흡수 특성을 나타내는 반사손실 (Reflection loss, $\mathrm{RL})$ 을 계산하였고 이를 Fig. 5(a)-5(e)에 RL 값을 주파수 $(f)$ 와 $10 \mathrm{~mm}$ 이하 범위의 두께 $(d)$ 의 함수인 2 차원 map으로 도시하였다. RL의 유전-자성 재료의 흡수능은 전송선 이론 [35]을 기반으로 한 식5, 식6를 통해 반사손실 $(\mathrm{RL})$ 값으 로 나타낸다.

$$
\begin{aligned}
& \frac{z_{\text {in }}}{z_{0}}=\sqrt{\mu_{r} / \varepsilon_{r}} \tanh \left[\mathrm{j} \frac{2 \pi f d}{c} \sqrt{\mu_{r} \times \varepsilon_{r}}\right] \\
& \mathrm{RL}(\mathrm{dB})=20 \log \frac{z_{\text {in }} / z_{0}-1}{z_{\text {in }} / z_{0}+1}
\end{aligned}
$$
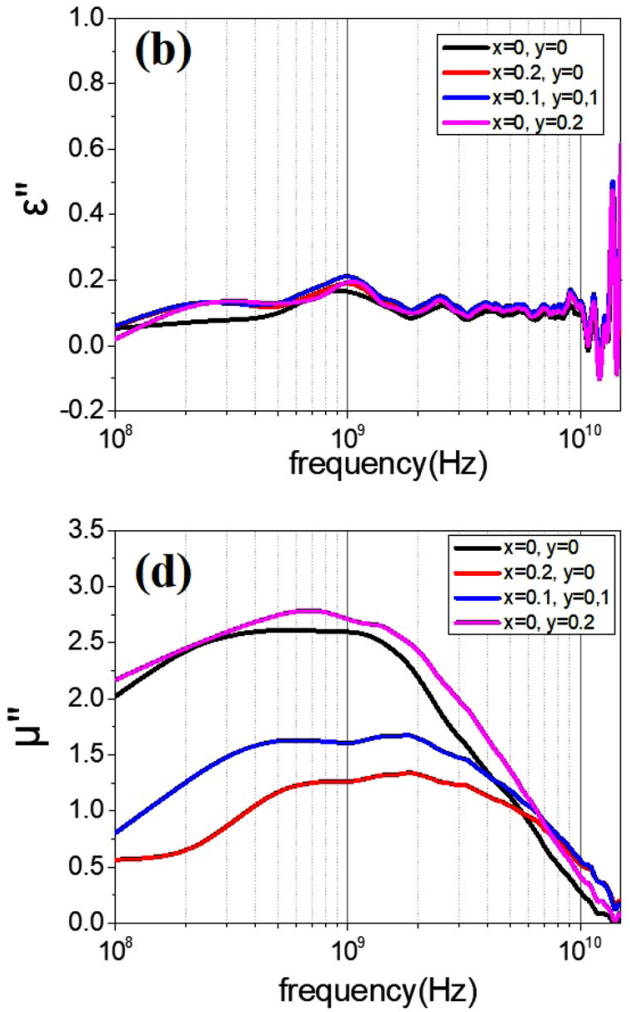

Fig. 3. (a, b) complex permittivity $\left(\varepsilon^{\prime}, \varepsilon^{\prime \prime}\right)$ and $(\mathrm{c}, \mathrm{d})$ complex permeability $\left(\mu^{\prime}, \mu^{\prime \prime}\right)$ spectra $(0.1 \mathrm{GHz} \leq f \leq 15 \mathrm{GHz})$ of $\left(\mathrm{Ni}_{0.5} \mathrm{Zn}_{0.5}\right)_{1-x-}$ ${ }_{y} \mathrm{Co}_{x} \mathrm{Cu}_{y} \mathrm{Fe}_{2} \mathrm{O}_{4}$ particle-epoxy composites. 
여기서 $\mathrm{Z}_{\text {inㅡㄴ }}$ 재료의 입사 임피던스, $\mathrm{Z}_{0}$ 는 자유 공간의 임피던스, $\varepsilon_{r}$ 은 $\varepsilon^{\prime}-j \varepsilon^{\prime \prime}$ 로 표현되는 복소 유전율, $\mu_{r}$ 은 $\mu^{\prime}-j \mu^{\prime \prime}$ 로 표현되는 복소 투자율, $f$ 는 입사 전자기파의 주 파수, $c$ 는 자유전자의 속도, $d$ 는 흡수체의 두께이다. 유전 율과 투자율은 두께에 무관한 함수이며, 주파수에 따라 확 보한 복소 유전율과 복소 투자율의 실수부와 허수부 값들 $\left(\varepsilon^{\prime}, \varepsilon^{\prime \prime}, \mu^{\prime}, \mu^{\prime \prime}\right)$ 과 0 에서 $10 \mathrm{~mm}$ 범위의 $d$ 값을 연속적으 로 지정하여 식 (3)에서 $\mathrm{Z}_{\mathrm{in}} / \mathrm{Z}_{0}$ 를 얻고 이를 식 (4)에 대 입하여 RL spectra를 얻게 된다 [36,37]. RL $(\mathrm{dB})$ 값은 절 대값이 큰 음의 값을 가질수록 우수한 흡수능을 갖는다. 높 은 흡수능을 보이기 위해서는 전자기파가 흡수체 표면에서 반사가 최소화되어야 하며 흡수체 내에는 유전적 또는 자 기적 손실기구가 존재하여야 한다. 그림 4(a)-4(d)에서 바 깥쪽 첫 번째 실선 영역은 $\mathrm{RL}<-10 \mathrm{~dB}$ 이하로 $90 \%$ 이상의 전자기파 에너지를, 두 번째 실선은 $\mathrm{RL}<-20 \mathrm{~dB}$ 이하로 $99 \%$ 이상, 세번째 실선은 $\mathrm{RL}<-30 \mathrm{~dB}$ 로 $99.9 \%$ 이상 전자기파의 에너지를 흡수할 수 있는 영역을 의미한다. 또한 위 식에 의하면 $\mathrm{Z}_{\mathrm{in}} / \mathrm{Z}_{0}$ 가 1 에 가까운 값을 가질수록 RL은 큰 음의 값, 곧 높은 전자기파 흡수능을 보이게 된다. 이를 만족하기 위해서는 손실기구와 관련되 유전율의 허수부 $\left(\varepsilon^{\prime \prime}\right)$, 투자율의 허수부 $\left(\mu^{\prime \prime}\right)$ 값 뿐만 아니
라 이들 $\varepsilon^{\prime}, \varepsilon^{\prime \prime}, \mu^{\prime}, \mu^{\prime \prime}$ 의 상대적인 크기와 주파수 및 두 께 관계도 중요하게 작용한다 [38-40].

그림 4(a)의 비치환 조성에서는 $f=2.6 \mathrm{GHz}$ 와 두께 $7.0 \mathrm{~mm}$ 에서 $\mathrm{RL}<-40 \mathrm{~dB}$ 의 가장 높은 흡수능이 발생하고 $f=2.6 \mathrm{GHz}$ 와 두께 $4 \mathrm{~mm}$ 부근에서 $\mathrm{RL}<-30 \mathrm{~dB}$ 의 두번 째 $\mathrm{RL}$ 최저점이 존재한다. $\mathrm{RL}<-10 \mathrm{~dB}$ 영역은 좌상-우하 방향으로 늘어져서 존재하는데, $\mathrm{Co}$ 가 치환된 그림 4(b)와 4(c)를 보면 4(a) 보다 고주파 방향으로, 그리고 낮은 두께 방향으로 흡수 영역이 이동해 가는 것을 확인 할 수 있다. 그림 4(d)의 $\mathrm{Cu}$ 만 $(x=0$ and $y=0.2)$ 치환된 경우 그림 4(a)의 비치환 샘플의 흡수 RL map과 유사하나 $R L<-10$ $\mathrm{dB}$ 영역이 두 곳으로 나뉜 점에서 차이를 보인다.

그림 5(a), 5(b)는 그림 4(a)-4(d)의 RL map상의 첫번 째, 두번째 최저 RL point의 두께에서 주파수에 따른 RL spectra를 보여준다. 그림 4 의 $\mathrm{RL}$ map 상의 $\mathrm{RL}_{\min 1}$ 및 $\mathrm{RL}_{\min 2}$ 지점에서 가로선을 각각 긋고, 이에 해당하는 $\mathrm{RL}$ 의 값의 profile을 도출하여 그림 $5(\mathrm{a})$, 그림 $5(\mathrm{~b})$ 로 나타낸 것으로 볼 수 있다. 치환 조성 $x, y$ 에 따른 복합체 샘플들 의 첫번째, 두번째 최대 흡수능을 보이는 RL 최저점의 값 들과 그 때의 두께와 주파수 값을 표 3에 각각 제시하였 다. 그림 5(a)에서 $\mathrm{Co}$ 만 치환된 $(x=0.2$ and $y=0)$ 샘플
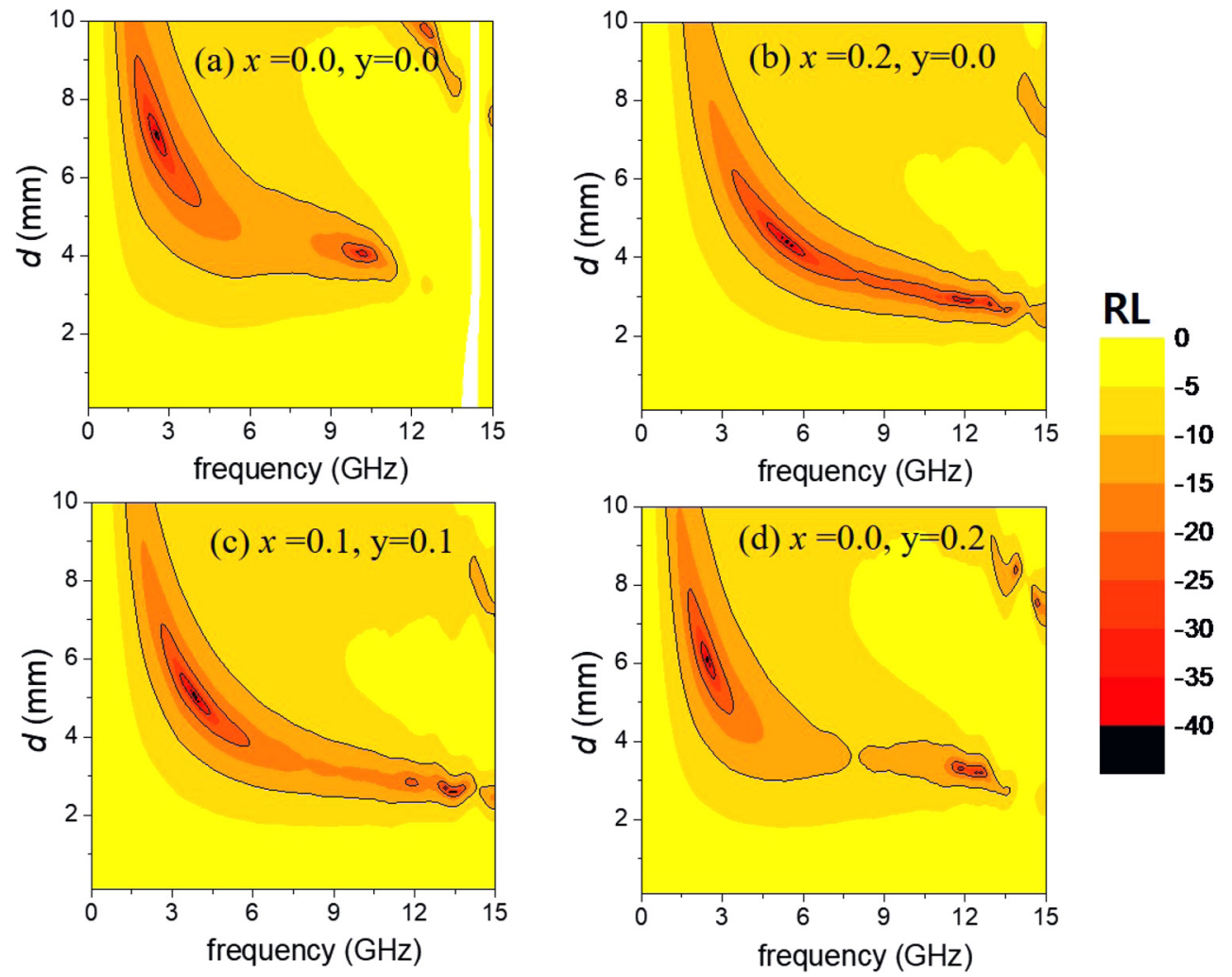

Fig. 4. RL map plots as a function of frequency and thickness for $\left(\mathrm{Ni}_{0.5} \mathrm{Zn}_{0.5}\right)_{1-x-y} \mathrm{Co}_{x} \mathrm{Cu}_{y} \mathrm{Fe}_{2} \mathrm{O}_{4}$ particle-epoxy composites (a) with $x=0$ and $y=0$, (b) $x=0.2$ and $y=0$, (c) $x=0.1$ and (d) $y=0.1, x=0$ and $y=0.2$. 
(a) first RL min.

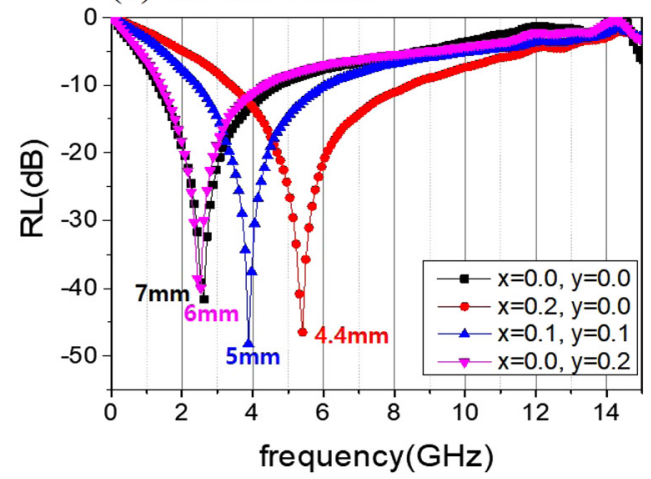

(b) second RL min.

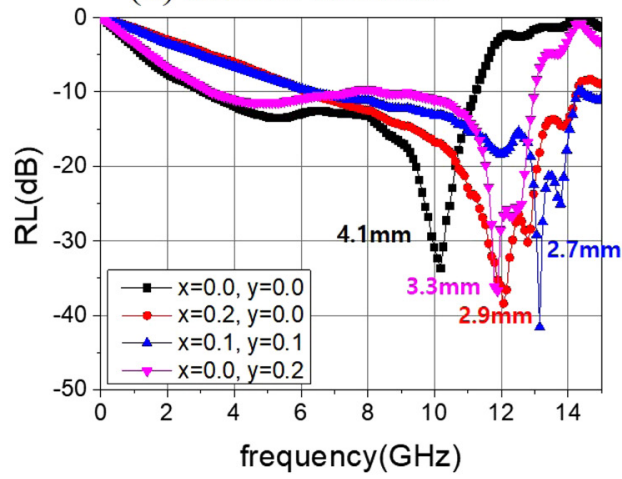

Fig. 5. $\mathrm{RL}$ spectra at the first and second $\mathrm{RL}$ minimum points of the $\left(\mathrm{Ni}_{0.5} \mathrm{Zn}_{0.5}\right)_{1-x-y} \mathrm{Co}_{x} \mathrm{Cu}_{y} \mathrm{Fe}_{2} \mathrm{O}_{4}$ particle-epoxy composites.

은 비치환 샘플 $(x=0$ and $y=0)$ 보다 높은 주파수, 보 다 낮은 두께에서 첫번째 $(f=5.4 \mathrm{GHz}, d=4.4 \mathrm{~mm}, \mathrm{RL}$ $=-47 \mathrm{~dB}$ ) 최대 흡수가 일어남을 알 수 있다. $\mathrm{Co}$ 의 치환에 따라 전자기파 흡수 주파수가 고주파 방향으로 이동하는 것은 결정자기이방성 증가에 따른 자기적 특성의 변화와 관련이 있다. 자기적 손실과 관련된 $\mu^{\prime \prime}$ spectra (그림 $3(\mathrm{~d})$ )가 $\mathrm{Co}$ 치환에 의해 고주파 방향으로 shift하였고, 이에 대응하여 그림 5(a)에서 최대 흡수 주파수 대역이 고주파 방향으로 이동한 것이다. 최대 흡수가 일어나는 최저 RL 점의 두께가 더 얇아진 것은 식 (4) 및 식 (5)에서의 임 피던스 매칭 특성과 관련된 것으로, 일반적으로 전자기파 의 파장이 짧아 질수록 최적 흡수 두께도 얇아지는 경향을 보인다. $\mathrm{Cu}$ 와 $\mathrm{Co}$ 가 함께 치환된 $(x=0.1$ and $y=0.1)$ 경 우 첫번째 $\mathrm{RL}$ 최저점은 비치환 조성 $(x=0$ and $y=0)$ 과 $\mathrm{Co}$ 가 치환된 $(x=0.2$ and $y=0)$ 조성의 샘플의 중간 정 도의 주파수와 두께 값을 보인다 (그림 5(a)). 이 역시 그 림 3(d)의 $\mu^{\prime \prime}$ spectra의 최대점의 주파수가 비치환 조성과 Co 치환 조성 $(x=0.2$ and $y=0)$ 샘플의 사이 값을 갖는 것과 관련이 있다. 투자율 spectra에서 비치환 조성과 큰 차이가 없는 $\mathrm{Cu}$ 치환 조성 $(x=0$ and $y=0.2)$ 의 경우 첫 번째 최대 흡수 지점의 $f=2.5 \mathrm{GHz}, d=6.0 \mathrm{~mm}$ 에서 $\mathrm{RL}$ $=-40 \mathrm{~dB}$ 로 그림 4(a) RL map과 그림 5(a)에서 확인할 수 있는 바와 같이 매우 유사한 흡수 특성을 보임을 알 수 있다. 그림 5(a)의 첫번째 RL 최저점에서 얻어지는 최저 반사 손실 값은 모두 $\mathrm{RL}<-40 \mathrm{~dB}$ 로 표 1 의 타 연구의 결과 보다 비교적 우수한 전자기파 흡수 특성을 보인다. 또한 그림 5(b)의 두번째 최저점에서 얻은 RL spectra에서 는 보다 낮은 두께로 광범위한 주파수에서 전자기파 흡수 특성을 보여 실용적 측면에서 중요성이 크다. 특히 $\mathrm{Co}$ 가 치환된 두 샘플의 경우 $(x=0.1$ and $y=0.1, x=0.2$ and
Table 3. First and second minimum reflection loss $\left(\mathrm{RL}_{\min 1}, \mathrm{RL}_{\mathrm{min} 2}\right)$, thicknesses $\left(d_{1}, d_{2}\right)$, and the frequenceis at minimum reflection loss points $\left(f_{\text {Rlmin } 1}, f_{\text {Rlmin } 2}\right)$ of $\left(\mathrm{Ni}_{0.5} \mathrm{Zn}_{0.5}\right)_{1-x-y} \mathrm{Co}_{x} \mathrm{Cu}_{y} \mathrm{Fe}_{2} \mathrm{O}_{4}$ particle-epoxy composites.

\begin{tabular}{cccccccc}
\hline$x$ & $y$ & $\begin{array}{c}\mathrm{RL}_{\min 1} \\
(\mathrm{~dB})\end{array}$ & $\begin{array}{c}d_{1} \\
(\mathrm{~mm})\end{array}$ & $\begin{array}{c}f_{\mathrm{RLmin} 1} \\
(\mathrm{GHz})\end{array}$ & $\begin{array}{c}\mathrm{RL}_{\min 2} \\
(\mathrm{~dB})\end{array}$ & $\begin{array}{c}d_{2} \\
(\mathrm{~mm})\end{array}$ & $\begin{array}{c}f_{\mathrm{RLmin} 2} \\
(\mathrm{GHz})\end{array}$ \\
\hline 0 & 0 & -41.6 & 7.0 & 2.62 & -33.6 & 4.1 & 10.2 \\
0.2 & 0 & -46.5 & 4.4 & 5.41 & -38.4 & 2.9 & 12.1 \\
0.1 & 0.1 & -48.2 & 5.0 & 3.88 & -41.6 & 2.7 & 13.1 \\
0 & 0.2 & -40.0 & 6.0 & 2.53 & -36.7 & 3.3 & 11.9 \\
\hline
\end{tabular}

$y=0), 3 \mathrm{~mm}$ 이하의 두께로 X-band 대역을 포함하는 $7 \sim 14 \mathrm{GHz}$ 의 넓은 범위에서 $\mathrm{RL}>-10 \mathrm{~dB}$ 을 만족함을 알 수 있다.

\section{4. 결 론}

본 연구에서는 $\mathrm{Cu}$ 와 $\mathrm{Co}$ 가 치환된 스피넬 페라이트 분말 $\left(\mathrm{Ni}_{0.5} \mathrm{Zn}_{0.5}\right)_{1-x-y} \mathrm{Co}_{x} \mathrm{Cu}_{y} \mathrm{Fe}_{2} \mathrm{O}_{4},(x=0$ and $y=0, x=0.2$ and $y=0, x=0.1$ and $y=0.1, x=0$ and $y=0.2)$ 을 졸겔법으 로 합성한 후 후열처리 공정을 통해 제조하였다. 모두 단 상의 스피넬상이 얻어졌으며 $\mathrm{Cu}$ 를 치환할 때 결정립이 매 우 크게 성장하는 것을 확인 할 수 있었다. 후열처리한 각 각의 조성의 자성 분말들을 epoxy 바인더와 혼합하여 주 파수 $(0.1 \leq f \leq 15 \mathrm{GHz})$ 에 따른 복소 유전율 및 투자율을 측정하고, 이 값들 이용하여 전송선 이론을 근거로 반사 손실 $(\mathrm{RL})$ 을 도출하여 전자기파 흡수 특성을 평가하였다. 유전율의 실수부 값은 $\mathrm{Co}$ 치환보다 $\mathrm{Cu}$ 의 첨가에 보다 민 감하게 변화하였으나 전자기파의 흡수와 관련된 유전율의 허수부 값은 모든 샘플에서 0 에 가까운 낮은 값을 보였다. 투자율 값은 주로 $\mathrm{Co}$ 의 치환에 의존하여 변화하였다. $\mathrm{Co}$ 
가 치환될수록 결정자기이방성의 증가로 인한 투자율의 허 수부 peak가 고주파 방향으로 shift하였다. 이에 따라 RL map과 RL spectra에서 나타나는 전자기파의 흡수 특성도 보다 높은 주파수와 낮은 두께 방향으로 이동해 가는 것을 확인할 수 있었다. 이상의 결과에서 $\mathrm{Co}$ 와 $\mathrm{Cu}$ 를 함께 치환 한 Ni-Zn 페라이트 - polymer 복합체는 고주파 자기 특 성 제어를 통한 수 십 수 $\mathrm{GHz}$ 범위 주파수 대역의 전 자기파를 흡수체로 매우 유용한 소재라고 할 수 있다. 약 $2.4 \mathrm{GHz}$ 대역에서 활용되고 있는 스마트 통신 기기의 RF 모듈, 방송 통신 중 $300 \mathrm{MHz} 3 \mathrm{GHz}$ 대역에서 활용되고 있는 UHF (Ultra High Frequency), 군사 분야에서 활용 되는 X-band 등 다양한 주파수 대역에 맞춰 전자파 흡수 체로써의 활용 가치가 높다고 판단된다.

\section{감사의 글}

본 연구는 2019-2020년도 과학기술정보통신부의 재원으 로 한국연구재단 (NRF-2017R1C1B2002394)의 지원과 교 육부의 재원으로 한국기초과학지원연구원 국가연구시설장 비진흥센터의 지원을 받은 기초과학연구역량강화사업 핵심 연구지원센터 조성 지원 과제에서 열-전기 핵심연구 지원 센터 (2019R1A6C1010047)를 조성하여 수행된 연구결과입 니다.

\section{REFERENCES}

1. K. Joseph, R. Wilson, and G. George, Materials for potential EMI shielding application: processing, properties and current trends, 1st ed., Elsevier, France (2019).

2. C.Y. Lee, H.G. Song, J.S. Jang, E.J. Oh, A.J. Epstein, and J. Joo, Synth. Met. 102, 1346 (1999).

3. P. Saini, V. Choudhary, B. P. Singh, R. B. Mathur, and S. K. Dhawan, Mater. Chem. Phys. 113, 919 (2009).

4. M. Yamaguchi, Y. Miyazawa, K. Kaminishi, H. Kikuchi, S. yabukami, K.I. Arai, and T. Suzuki, J. Magn. Magn. Mater. 268, 170 (2004).

5. P. Singh, V. K. Babbar, A. Razdan, R. K. Puri, and T. C. Goel, J. Appl. Phys. 87, 4362 (2000).

6. K. A. Korolev, J. S. Mccloy, and M. N. Afsar, J. Appl. Phys. 111, 07E113 (2012).

7. J. Smit and H. P. J. Wijin, Ferrites, Philips' Technical Library, pp.136-176, Eindhoven, Netherlands (1959).

8. S. Chikazumi, Physics offerromagnetism, 2nd ed., pp. $197-$ 221, Clarendon Press, Oxford (1997).

9. J. Gunjakar, A. More, K. Gurav, and C. Lokhande, Appl.
Surf. Sci. 18, 5844 (2008).

10. A. Lassoued, M. Lassoued, B. Dkhil, S. Ammar, and A. Gadri, J. Meter. Sci. 29, 7333 (2018).

11. Y. Liu, S. Wei, B. Xu, Y. Wang, H. Tian, and H. Tong, J. Magn. Magn. Mater. 349, 57 (2014).

12. K. R. Mun and Y. M. Kang, J. Korean Magn. Soc. 28, 1 (2018).

13. S. Y. An, I. S. Kim, S. H. Son, S. Y. Song, and J. W. Hahn, J. Korean Magn. Soc. 20, 182 (2010).

14. L. Wang, H. Dong, J. Li, J. Hua, S. Xu, M. Feng, and H. Li, Ceram. Int. 40, 10323 (2014).

15. J. Azadmanjiri, Mater. Chem. Phys. 109, 109 (2008).

16. Y.-H. Ryu and S.-S. Kim, J. Korea powder Metall. Inst. 21, 429 (2014).

17. S. T. Mahmud, A. K. M. Akther Hossain, A. K. M. Abdul Hakim, M. Seki, T. Kawai, and H. Tabata, J. Magn. Magn. Mater. 305, 269 (2006).

18. Z. Feng, D. Li, L. Wang, Q. Sun, P. Xing, and M. An, Mater. Lett. 233, 267 (2018).

19. X. Peng, K. Peng, and W. Zhang, Mater. Res. Bull. 100, 138 (2018).

20. L. Wang, H. Dong, J. Li, J. Hua, S. Xu, M. Feng, and H. Li, Ceram. Int. 40, 10323 (2014).

21. A. Albuquerque, J. Ardisson, and W. Macedo, J. Magn. Magn. Mater. 192, 277 (1999).

22. M. Zhang, Q. Liu, Z. Zi, Y. Dai, X. Zhu, Y. Sun, and J. Dai, Sci. China. Tech. Sci. 56, 13 (2013).

23. Y. Liu, S. Wei, Y. Wang, H. Tian, H. Tong, and B. Xu, Phys. Pro. 50, 43 (2013).

24. N. Chen and M. Gu, O. J. Mater. 2, 37 (2012).

25. S. Abbas, H. John, and A. Fraih, Indian. J. Sci. Tech. 10, 1 (2017).

26. Y. Chu, B. Zhang, and J. Xiang, Adv. Mater. 631-632, 429 (2013).

27. J. Xie, M. Han, L. Chen, R. Kuang, and L. Deng, J. Magn. Magn. Mater. 314, 37 (2007).

28. J.-E. Yoo, T. W. Hong, and Y.-M. Kang, J. Kor. Magn. Soc. 28, 219 (2018).

29. J.-E. Yoo and Y.-M. Kang, J. Magn. Magn. Mater. 513, 167075 (2020).

30. K.-R. Mun and Y.-M. Kang, J. Magn. 24, 499 (2019).

31. L. M. Levinson, Electronic Ceramics: Properties: Devices, and Applications, p.156, Marcel Dekker, New York (1988).

32. T. Tsutaoka, J. Appl. Phys. 93, 2789 (2003).

33. J. L. Snoek, Physica 4, 207 (1948).

34. T. Nakamura, J. Appl. Phys. 88, 348 (2000). 
35. Y. Naito and K. Suetake, IEEE Trans. Microw. Theory Tech. 19, 65 (1971).

36. M.-H. Park and Y.M. Kang, J. Magn. Magn. Mater. 491, 165628 (2019).

37. E.-S. Lim, T.W. Hong, and Y.-M. Kang, J. Kor. Magn. Soc. 30, 31 (2020).
38. E.-S. Lim and Y.-M. Kang, Mater. Today Comm. 25, 101411 (2020).

39. H.-S. Cho and S.-S. Kim, Korean J. Met. Mater. 57, 741 (2019).

40. P. Jang, Korean J. Met. Mater. 56, 680 (2018). 